\title{
An acid-base disorders analysis with the use of the Stewart approach in patients with sepsis treated in an intensive care unit
}

\author{
Jakub Szrama, Piotr Smuszkiewicz \\ Department of Anesthesiology, Intensive Care and Pain Management, \\ Medical University Hospital, Poznan, Poland
}

\begin{abstract}
Background: Patients with sepsis admitted to the intensive care unit often present with acid-base disorders. As the traditional interpretation might be clinically misleading, an alternative approach described by Stewart may allow one to quantify the individual components of acid-base abnormalities and provide an insight into their pathogenesis. The aim of our study was to compare the traditional and Stewart approaches in the analysis of acid-base disturbance. Methods: We analyzed arterial blood gases (ABG) taken from 43 ICU septic patients from admission to discharge categorising them according to SBE values. The traditional concept analysis was compared with the physicochemical approach using the Stewart equations.

Results: $990 \mathrm{ABGs}$ were analysed. In the $\mathrm{SBE}<-2 \mathrm{mEq} \mathrm{L} \mathrm{L}^{-1}$ group, hyperlactatemia was observed in $34.7 \% \mathrm{ABG}$, hypoalbuminemia in $100 \%$ and SIG acidosis in $42 \%$ ABG. Moreover, a Cl/Na ratio $>0.75$ was present in $96.9 \%$ ABG. In the normal range SBE group, elevated lactates were present in $21.3 \% \mathrm{ABG}$, SIG acidosis in $14.9 \%$, elevated $\mathrm{Cl} / \mathrm{Na}$ ratio in $98.4 \%$ and hypoalbuminemia in all $324 \mathrm{ABG}$. In the metabolic alkalosis group (SBE $>+2 \mathrm{mEq} \mathrm{L}^{-1}$ ), hyperlactatemia was observed in $18.4 \%$ ABG, SIG acidosis in 5\% ABG, Cl/Na ratio > 0.75 in $88.8 \%$, while $99.1 \%$ samples revealed hypoalbuminemia.

Conclusion: The use of the Stewart model may improve our understanding of the underlying pathophysiological mechanism and the true etiology of the derangements of acid-base disorders. Indeed, it proves that patients may suffer from mixed arterial blood gas disorders hidden under normal values of SBE and $\mathrm{pH}$.
\end{abstract}

Key words: acid-base disorders, Stewart approach, critical care, sepsis

Anaesthesiology Intensive Therapy 2016, vol. 48, no 3, 180-184

Patients with severe sepsis or septic shock admitted to the intensive care unit (ICU) present a wide variability of acid-base disorders, with metabolic acidosis being one of the most frequently observed. The presence of metabolic acidosis is connected with greater morbidity and mortality in the ICU [1]. Some of these patients suffer from abnormalities with co-existing metabolic acidosis and alkalosis. Generally, acid-base disorders are analyzed according to the so-called traditional concept, which includes the determination of the standard base excess (SBE), bicarbonate concentration in the plasma $\left(\mathrm{HCO}_{3}^{-}\right)$and the anion gap (AG). When there is just one simple acid-base disorder present, the traditional concept is sufficient. On the other hand, it provides no detailed knowledge on the source of the problem [2]. The SBE is a calculated figure, derived from $\mathrm{PaCO} 2$ and arterial $\mathrm{pH}$, whose calculation assumes normal plasma protein and electrolyte contents [3]. The AG derived from arterial gasometry ignores the role of the main nonbicarbonate buffers in the blood such as plasma proteins and inorganic phosphate. Thus, when electrolyte or protein abnormalities are present, which almost always is a problem in ICU patients, the traditional interpretation might be clinically misleading.

An alternative to this conventional model is the mathematical model based on physicochemical principles described by Stewart [4] and modified by Figge et al. [3, 5]. 
The model proposes that three variables determine $\mathrm{pH}$ in plasma by primarily changing the degree of water dissociation into hydrogen and hydroxide ions: the strong ion difference (SID, the difference between fully dissociated anions and cations), the $\mathrm{PaCO}_{2}$, and the total weak acid concentration (consisting mainly of albumin and phosphate). According to Stewart, there may be five main metabolic acid-base derangements, that is: the strong ion gap acidosis (SIG acidosis), caused by the presence of unidentified anions; low SID acidosis (mainly hyperchloremic); high SID alkalosis (mainly hypochloremic and/or hypernatremic); acidosis caused by an increase in weak acid concentration (mainly phosphates); and alkalosis caused by low weak acid concentration (mainly hypoalbuminaemia) [6]. The Stewart method allows the clinician to quantify the individual components of acid-base abnormalities and provides an insight into their pathogenesis. Using physicochemical evaluation, a few studies have shown that the traditional approach often fails to identify acid-base disorders in the population of critically ill patients [6].

The debate is still ongoing and there are no conclusions which would suggest using one method over another, which displays the need for studies in this field. Therefore, the aim of our study was to compare the traditional approach and the physicochemical method of the Stewart analysis of acidbase disturbance in a population of ICU septic patients, with a special interest in quantifying the individual components of acid-base disorders.

\section{METHODS}

This observational study was conducted in a single, mixed medical and surgical adult ICU with 7 beds in a clinical hospital in Poland. It included 43 septic patients admitted to the ICU between June 2012 and July 2013. Patients were considered eligible for the study if they had a diagnosis of septic shock according to the current definition [7] and had all the necessary laboratory results in order to perform a mathematical analysis according to the Stewart approach. The study was approved by the institutional ethics committee. Because the blood tests and data collected in the study all comprised standard care, informed consent was waived. Demographic, clinical and laboratory data from admission to discharge of the patients were collected and the Acute Physiology and Chronic Health Evaluation II (APACHE) score was calculated. Some of the acid-base status variables were gained from an arterial blood gas analysis, that is: $\mathrm{pH}, \mathrm{paO}_{2}$, $\mathrm{paCO}_{2}, \mathrm{SBE}, \mathrm{HCO}_{3}$, lactate and electrolyte concentration. In order, to analyse blood arterial gasometry, a Radiometer abl 90 flex gasometry analyser was used. Based on the SBE, metabolic acidosis was defined as $\mathrm{SBE}<-2 \mathrm{mEq} \mathrm{L}^{-1}$; normal metabolic acid-base status was defined as SBE between -2 and 2; metabolic alkalosis was defined as SBE $>2 \mathrm{mEq} \mathrm{L}^{-1}$.
Some of the variables were calculated. The AG was calculated as follows: $\mathrm{AG}=\left[\mathrm{Na}^{+}\right]+\left[\mathrm{K}^{+}\right]-\left[\mathrm{HCO}^{-}\right]-\left[\mathrm{Cl}^{-}\right]$. The anion gap was corrected for the effect of an abnormal albumin concentration using the following formula: AGcorr $=A G+$ $+0.25 \times\left(40\right.$ - albumin in $\left.\mathrm{g} \mathrm{L}^{-1}\right)[8]$.

A physicochemical analysis was performed using the Stewart equations [4] modified by Figge et al. [3, 5] in order to consider the effects of plasma proteins. The Stewart approach takes into account the so-called Strong lons Difference [SID], which is the difference between fully dissociated ions. This includes SIDa, meaning apparent SID, which was calculated as follows: SIDa $=\left[\mathrm{Na}^{+}\right]+\left[\mathrm{K}^{+}\right]+\left[\mathrm{Ca}^{2+}\right]+\left[\mathrm{Mg}^{2+}\right]$ $-\left[\mathrm{Cl}^{-}\right]-\left[\right.$lactate $\left.{ }^{-}\right]$(all concentrations in miliequivalents per litre).There is also SIDe, meaning effective SID, which is calculated as follows: $\mathrm{SIDe}=2.46 \times 10^{\mathrm{pH}-8} \times \mathrm{paCO}_{2}[\mathrm{~mm}$

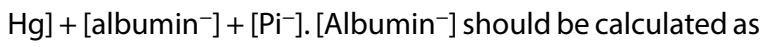
follows: [albumin ${ }^{-}$] $=$[albumin] $\times(0.123 \times \mathrm{pH}-0.631)$ and inorganic phosphate $\left[\mathrm{Pi}^{-}\right]$(millimolar): $\left[\mathrm{Pi}^{-}\right]=[\mathrm{Pi}] \times(0.309 \times$ $\mathrm{pH}-0.469$ ) [7]. The strong ion gap (SIG) which is the measure of the presence of unidentified anions [UA] was calculated as the difference between apparent SID and effective SID: SIG =SIDa - SIDe, which physiologically should be equal $[4,5]$. A positive value was defined as representing the presence of $U A$, which must be included to account for the measured $\mathrm{pH}$. A chloride to sodium ratio was also calculated, with SID acidosis being diagnosed when the $\mathrm{Cl} / \mathrm{Na}$ ratio was $>0.75$, while SID alkalosis was diagnosed when the $\mathrm{Cl} / \mathrm{Na}$ ratio was < 0.75 [6]. Hypoalbuminemia was defined as a serum albumin concentration below $35 \mathrm{~g} \mathrm{~L}^{-1}$. Hyperlactatemia was defined as lactate levels greater than $2 \mathrm{mmol} \mathrm{L}^{-1}$.

Continuous data were presented as a mean with a standard deviation or median (Me) with a lower $\left(Q_{1}\right)$ and upper quartile $\left(Q_{3}\right)$, while ordinal data were presented as a number with a percentage. The results were analyzed statistically with the t-test and Mann-Whitney test (most data did not pass the Shapiro-Wilk normality test). A $P<0.05$ was considered statistically significant.

\section{RESULTS}

Forty-three septic patients admitted to the ICU were included in the study. Their demographic and clinical data are presented in Table 1. Moreover, 990 arterial blood gas (ABG) samples were gained from these patients during their ICU stay, with an average of $23 \mathrm{ABG}$ ser patient in order to analyse gas exchange status and acid-base disorders. The arterial blood gases were categorized into three groups according to the traditional approach, with $\mathrm{SBE}<-2 \mathrm{mEq} \mathrm{L}^{-1}$ categorized as metabolic acidosis, SBE in the range $-2-$ $+2 \mathrm{mEq} \mathrm{L} \mathrm{L}^{-1}$ as normal acid-base status and SBE $>2 \mathrm{mEq} \mathrm{L}^{-1}$ as metabolic alkalosis. The number of samples which met the criteria of hyperlactatemia, hypoalbuminemia, SIG acidosis and elevated $\mathrm{Cl} / \mathrm{Na}$ ratio for each of the subgroups is 
Table 1. Demographic and clinical data. Presented as medians $\left(\mathrm{Q}_{1}-\mathrm{Q}_{3}\right)$ or $\mathrm{n}(\%)$ as otherwise indicated

\begin{tabular}{lc}
\hline Variable & Results \\
\hline Age (years) & $52(39 ; 68)$ \\
Males & $29(67 \%)$ \\
Average of ABGs per patient [mean] & 23 \\
Days in the ICU & $14(8-22)$ \\
Survivors & $35(81 \%)$ \\
Medical/Surgical & $27(63 \%) / 16(37 \%)$ \\
APACHE II score & $14(10-24)$ \\
Body mass (kg) & $70(60-84)$ \\
Mechanical ventilation at admission & $43(100 \%)$ \\
Vasopressors at admission & $43(100 \%)$ \\
WBC (G L-1) & $14.7(10.8-19.4)$ \\
Serum creatinine (mg dL ${ }^{-1}$ ) & $0.94(0.62-1.69)$ \\
CRP (mg dL ${ }^{-1}$ ) & $127.5(98.6-204.8)$ \\
\hline APACHE - Acute Physiology and Chronic Health Evaluation; CRP - C-reactive \\
protein; ICU - intensive care unit; Me - median; Q1 - lower quartile; \\
Q3 - upper quartile
\end{tabular}

presented in Table 2. Taken all together, hypoalbuminemia was the most frequent disorder related to Stewart important acid-base disorders, and which was present in $99.6 \%$ of the analyzed samples. Low SID acidosis revealed by an increased $\mathrm{Cl} / \mathrm{Na}$ ratio was the most frequent cause of acidosis, and which was present in $93.5 \%$ of the samples, while hyperlactatemia was revealed in $22.5 \%$ of the analyzed samples. Finally, 153 (15.5\%) out of 990 ABG met the criteria of SIG acidosis according to the Stewart approach, proving the presence of unidentified anions.

An analysis of cases with hyperlactatemia $>2 \mathrm{mmol} \mathrm{L}^{-1}$ was performed by categorizing the results according to low/ /normal and elevated SBE values $\left(<2 \mathrm{mmol} \mathrm{L}^{-1}\right.$ or $\left.>2 \mathrm{mmol} \mathrm{L}^{-1}\right)$. 225 samples met the criteria of elevated lactate levels. We observed that 88 (39.1\%) of arterial blood gases had SBE > $2 \mathrm{mmol} \mathrm{L}^{-1}$ despite elevated lactate levels. Patients with SBE > 2 had higher $\mathrm{pH}$ and bicarbonate values $(7.34 \pm 0.15$ vs $7.4 \pm$ $\pm 0.05 ; 21.38 \pm 4.8$ vs $28.17 \pm 2.1$, respectively, with $P<0.0000001$ ). The most important parameters of acid-base status analysis for ABG with lactate $>2 \mathrm{mmol} \mathrm{L}^{-1}$ are presented in Table 3 .

Table 2. Stewart important acid-base disorders in each of the subgroups. Presented as medians $\left(\mathrm{Q}_{1}-\mathrm{Q}_{3}\right)$ or $\mathrm{n}(\%)$

\begin{tabular}{|c|c|c|c|}
\hline & $\mathrm{SBE}<-2 \mathrm{mEq} \mathrm{L}^{-1}$ & $-2 \mathrm{mEq} \mathrm{L}^{-1}<\mathrm{SBE}<2 \mathrm{mEq} \mathrm{L}^{-1}$ & $\mathrm{SBE}>2 \mathrm{mEq} \mathrm{L}^{-1}$ \\
\hline Number of samples & 193 & 324 & 473 \\
\hline Patients with lactate $>2 \mathrm{mmol} \mathrm{L}^{-1}$ & $67(34.7 \%)$ & $69(21.3 \%)$ & $87(18.4 \%)$ \\
\hline Patients with SIG acidosis & $82(42 \%)$ & $48(14.9 \%)$ & $23(5 \%)$ \\
\hline Patients with albumins $<35 \mathrm{~g} \mathrm{~L}^{-1}$ & $193(100 \%)$ & $324(100 \%)$ & $469(99.1 \%)$ \\
\hline Patients with $\mathrm{Cl} / \mathrm{Na}>0.75$ & $187(96.9 \%)$ & $319(98.4 \%)$ & $420(88.8 \%)$ \\
\hline $\mathrm{pH}$ & $7.35(7.27-7.40)$ & $7.45(7.40-7.48)$ & $7.47(7.44-7.49)$ \\
\hline $\mathrm{paCO}_{2}(\mathrm{~mm} \mathrm{Hg})$ & $36.7(32.4-44.1)$ & $35.5(32.0-41.0)$ & $39.4(36.3-43.6)$ \\
\hline SIDa $\left(\mathrm{mmol} \mathrm{L}^{-1}\right)$ & $30.5(27.1-33.6)$ & $32(29.6-34.0)$ & $34.3(32.4-36.2)$ \\
\hline SIDe $\left(\mathrm{mmol} \mathrm{L}^{-1}\right)$ & $29.1(27.2-31.1)$ & $32.7(31.3-34.3)$ & $36.6(34.7-38.8)$ \\
\hline Atot $\left(\mathrm{mmol} \mathrm{L}^{-1}\right)$ & $8.5(7.4-9.4)$ & $8.3(7.2-9.3)$ & $8.0(6.5-9.1)$ \\
\hline
\end{tabular}

SBE — standard base excess; SIG — strong ion gap; SIDa — apparent strong ion difference; SIDe — effective strong ion difference; Atot — weak acid concentration; Me - median; Q1 - lower quartile; Q3 - upper quartile

Table 3. Acid-base and electrolyte data for $A B G$ with lactate $>2$ mmol L-1. Presented as means $\pm S D$ or medians $\left(Q_{1}-Q_{3}\right)$

\begin{tabular}{|c|c|c|c|}
\hline Variable & $\mathrm{BE}<2 \mathrm{mEq} \mathrm{L}^{-1}$ & $\mathrm{BE}>2 \mathrm{mEq} \mathrm{L}^{-1}$ & $P$ value \\
\hline Sodium $\left(\mathrm{mmol} \mathrm{L}^{-1}\right)$ & $136(133-139)$ & $135.4(132-138)$ & 0.34 \\
\hline Chloride $\left(\mathrm{mmol} \mathrm{L}^{-1}\right)$ & $109(105-111)$ & $106(102-110)$ & $<0.001$ \\
\hline Phosphate (mmol L-1) & $1.5(1.0-1.8)$ & $1(0.9-1.3)$ & $<0.001$ \\
\hline $\mathrm{paCO} 2(\mathrm{~mm} \mathrm{Hg})$ & $40.4 \pm 10.3$ & $39.0 \pm 6.9$ & 0.36 \\
\hline Albumin $\left(\mathrm{g} \mathrm{L}^{-1}\right)$ & $18.4 \pm 4.5$ & $19.0 \pm 5.7$ & 0.38 \\
\hline Urea $\left(\mathrm{mg} \mathrm{dL}^{-1}\right)$ & $65(26-83)$ & $25(15-46)$ & $<0.001$ \\
\hline Lactate $\left(\mathrm{mmol} \mathrm{L}^{-1}\right)$ & $3.1(2.2-5.0)$ & $2.4(2.2-3.4)$ & $<0.001$ \\
\hline $\mathrm{Cl} / \mathrm{Na}$ & $0.80(0.78-0.81)$ & $0.78(0.76-0.79)$ & $<0.001$ \\
\hline AGcorr (mmol L-1) & $14.3(11.6-17.6)$ & $10.7(9.0-12.6)$ & $<0.001$ \\
\hline $\mathrm{SIG}\left(\mathrm{mmol} \mathrm{L}^{-1}\right)$ & $2.7(0.5-5.3)$ & $-0.2(-1.6-1.7)$ & $<0.001$ \\
\hline
\end{tabular}

Agcorr — anion gap corrected for albumins; Me — median; Q1 - lower quartile; Q3 - upper quartile; BE — base excess; SIG — strong ion gap 


\section{DISCUSSION}

The performed study revealed that intensive care unit patients may suffer from acid-base disorders despite having normal pH or SBE values. The Stewart approach, in comparison to the traditional equation, allowed one to discover the underlying acid-base derangements and to quantify them enabling appropriate treatment.

Nearly all patients in the analyzed subgroups of patients with $\mathrm{BE}<-2 \mathrm{mEq} \mathrm{L}{ }^{-1}, \mathrm{BE}$ between -2 and $2 \mathrm{mEq}$ $\mathrm{L}^{-1}$ and $\mathrm{BE}>2 \mathrm{mEq} \mathrm{L}^{-1}$ suffered from metabolic alkalosis caused by hypoalbuminemia and low SID acidosis caused by a decreased difference between strong ions, mainly sodium and chloride. This second derangement is often referred as hyperchloremic acidosis, as hyperchloremia seems to be a more frequent cause of decreased SID.

Hyperchloremia is a frequent cause of metabolic acidosis in critically ill patients. In children with diabetic ketoacidosis, hyperchloremia is the dominant metabolic component of the acidosis after 12 hours of treatment, comprising $98 \%$ of the base deficit and often slowing the recovery of metabolic acidosis in the patient [9]. Infusion of isotonic saline solution, which has equal concentrations of sodium and chloride $\left(154 \mathrm{mmol} \mathrm{L}^{-1}\right)$, results in a reduction of SID, which, in turn, produces an increase in the number of hydrogen ions in order to preserve electrical neutrality [10]. Although studies of ICU patients have failed to detect a significant effect on survival attributable to hyperchloremic acidosis, hyperchloremia has been shown to cause hypotension, renal dysfunction, and increment in plasma cytokine levels [11]. Therefore, our finding that a normal SBE or $\mathrm{pH}$ values do not exclude the presence of low SID acidosis (mainly caused by hyperchloremia) may be clinically relevant.

Another important finding was the fact that in every subgroup of patients with $B E<-2 \mathrm{mEq} \mathrm{L}^{-1}, \mathrm{BE}$ between -2 and $2 \mathrm{mEq} \mathrm{L}^{-1}$ and $\mathrm{BE}>2 \mathrm{mEq} \mathrm{L^{-1 }}$ there were episodes of SIG acidosis. Recently, Noritomi et al. [12] found that patients with severe sepsis and septic shock exhibit a complex metabolic acidosis at ICU admission, caused predominantly by hyperchloremia and unmeasured anions (UA) acidosis. The same results were presented by Mallat, with hyperchloraemia and SIG acidosis affecting $70 \%$ of analysed septic patients [13]. Despite the awareness of the existence of UA and SIG acidosis, the source and biochemical nature of UA are unclear. These anions may be generated in peripheral tissues during global hypoxic states [14]. In addition, it has been shown that the concentrations of anions normally associated with the Krebs acid cycle are elevated in the plasma of patients with high AG metabolic acidosis [15]. High (preresuscitation) SIG levels at ICU admission are known to be related to the presence of sepsis, as well as renal and hepatic dysfunction, and are also probably a marker of tis- sue hypoperfusion [16]. Some studies [17, 18] found a clear association between high SIG levels and mortality, whereas one study did not [19]. The prognostic significance of high SIG levels during admission is probably more relevant when preresuscitation values are measured [19]. However, considering its association with unfavourable outcomes and specific disease states if measured during admission, it is reasonable to assume that increased SIG levels are a marker of tissue damage. Therefore, the possibility of increased SIG levels in patients with an apparently normal acid-base state may have clinical implications

Quite surprising might be the fact that patients with SBE in the reference range, or SBE $>2 \mathrm{mEq} \mathrm{L}^{-1}$, had still a coexistence of metabolic acidosis (in some cases three acidotic derangements), with the net SBE $>-2 \mathrm{mEq} \mathrm{L}^{-1}$ mainly caused by hypoalbuminemic metabolic alkalosis, and which was the most frequent derangement observed in our study.

Fencl et al. [6] has already demonstrated that SBE fails as a measure of metabolic acidosis in critically ill patients. In a study by Mallat et al. [13] low SID went unnoticed by changes in SBE because the low SID acidosis was masked by the alkalizing effect of hypoalbuminemia, present in all patients. However, even critically ill patients with an apparently normal acid-base state according to the conventional criteria $\left(\mathrm{pH}\right.$ and both $\mathrm{BE}$ and $\mathrm{pCO}_{2}$ within the reference range) have an underlying mixed acid-base disorder that emerged using the Stewart approach. Compared with data reported from healthy subjects $[1,19]$, this metabolic disorder is characterized by a combination of a low SIDa (caused by hyperchloremia, reflected by the decreased $\mathrm{Na}-\mathrm{Cl}$ difference), high SIG (both acidifying effects), and a low level of the weak acid albumin (alkalinizing effect). Apparently, traditional methods of assessing acid-base status fail to diagnose complicated acid-base disorders in critically ill patients.

The analysis of the acid-base status of ABG samples with elevated lactate levels according to the Stewart method revealed the real reason as to why some of these samples had $\mathrm{SBE}>2 \mathrm{mEq} \mathrm{L}^{-1}$. While one may consider that the alkalotic SBE in the presence of increased lactate levels is probably caused by hypoalbuminemia, our study and those of others [20] do not confirm this, with albumin concentrations comparable in both $\mathrm{SBE}<2 \mathrm{mEq} \mathrm{L}^{-1}$ and $\mathrm{SBE}>2 \mathrm{mEq} \mathrm{L}^{-1}$ groups. However, we found that patients with $\mathrm{SBE}>2 \mathrm{mEq} \mathrm{L}^{-1}$ had lower phosphate levels, with phosphate being one of the weak acids with acidotic properties. Another finding was higher urea concentrations and higher SIG values in the $\mathrm{SBE}<2 \mathrm{mEq} \mathrm{L}^{-1}$ group. Thus, probably the organic acids present in the kidney failure and unidentified anions may be the reason for lower SBE values in those ABG samples.

The limitations of this study include the fact that as the analysed patients at the moment of admission to the ICU had already undergone some amount of fluid resuscitation, 
catecholamin infusions and/or antibiotics, either in the operating theatre, emergency department or other ICUs, the APACHE II score or lactate levels probably had relatively low values. Furthermore, as the arterial blood gasometries analysed included samples taken from patients who had stayed in the ICU for more than one week, the electrolyte concentration in the serum and the acid-base disorder interpretation could have been affected by fluid therapy, renal replacement therapy, parenteral nutrition or diuretics administration during the ICU hospitalisation. The fact that all of the patients required mechanical ventilation, which allows one to manipulate minute ventilation and arterial carbon dioxide values, might have affected the metabolic compensation mechanisms. Nevertheless, the aim of the study was to compare two different interpretative models (the traditional and Stewart approaches) analysing the same ABG samples.

In conclusion, we believe that use of the Stewart model may improve our understanding of the underlying pathophysiological mechanisms that lead to important changes in the acid-base balance. It might seem reasonable to include electrolyte, albumin, lactate and phosphate concentrations in the analysis of acid-base disorders in ICU patients. Considering patients with metabolic acidosis according to traditional approach, the Stewart model gives us knowledge about the true etiology of the derangements. Furthermore, the Stewart model proves that despite normal $\mathrm{pH}$ and normal or alcalotic SBE values, patients may suffer from mixed arterial blood gas disorders with coexisting metabolic acidosis hidden under those normal values and unrevealed by the traditional approach.

\section{ACKNOWLEDGEMENTS}

1. Conflict of interest - none.

2. Source of founding - none.

\section{References:}

1. Gunnerson KJ, Kellum JA: Acid-base and electrolyte analysis in critically ill patients: are we ready for the new millennium? Curr Opin Crit Care 2003; 9: 468-473.

2. Cusack RJ, Rhodes $A$, Lochhead $P$ et al.: The strong ion gap does not have prognostic value in critically ill patients in a mixed medical/surgical adult ICU. Intensive Care Med 2002; 28: 864-869.

3. Figge J, Rossing $T H$, Fencl V: The role of serum proteins in acidbase equilibria. J Lab Clin Med 1991; 117: 453-467.

4. Stewart PA: Modern quantitative acid-base chemistry. Can J Physiol Pharmacol 1983; 61: 1444-1461.

5. Figge J, Mydosh T, Fencl V: Serum proteins and acid-base equilibria: a follow-up. J Lab Clin Med 1992; 120: 713-719.
6. FenclV, Jabor A, Kazda A et al.: Diagnosis of metabolic acid-base disturbances in critically ill patients. Am J Resp Crit Care Med 2000; 162: 2246-2251.

7. Bone RC, sibbald Wj, Sprung CL: The ACCP-SCCM consensus conference on sepis and organ failure. Chest 1992; 101: 1481-1483.

8. Feldman $M$, Soni N, Dickson B: Influence of hypoalbuminemia or hyperalbuminemia on the serum anion gap. J Lab Clin Med 2005; 146: 317-320.

9. Mrozik LT, Yung M: Hyperchloraemic metabolic acidosis slows recovery in children with diabetic ketoacidosis: a retrospective audit. Aust Crit Care 2009; 22: 172-177. doi: 10.1016/j. aucc.2009.05.001.

10. Scheingraber S, Rehm M, Sehmisch C, Finsterer U: Rapid saline infusion produces hyperchloremic acidosis in patients undergoing gynecologic surgery. Anesthesiology 1999; 90: 1265-1270.

11. Kellum JA, Song M, Almasri E: Hyperchloremic acidosis increases circulating inflammatory molecules in experimental sepsis. Chest 2006; 130: 962-967.

12. Noritomi DT, Soriano FG, Kellum JA et al.: Metabolic acidosis in patients with severe sepsis and septic shock: a longitudinal quantitative study. Crit Care Med 2009; 37: 2733-2739.

13. Mallat J, Michel D, Salaun Pet al.: Defining metabolic acidosis in patients with septic shock using Stewart approach. Am J Emerg Med 2012; 30: 391-398. doi: 10.1016/j.ajem.2010.11.039.

14. Kaplan LJ, Kellum JA: Initial pH, base deficit, lactate, anion gap, strong ion difference, and strong ion gap predict outcome from major vascular injury. Crit Care Med 2004; 32: 1120-1124 .

15. Forni LG, McKinnon W, Lord GA et al.: Circulating anions usually associated with the Krebs cycle in patients with metabolic acidosis. Crit Care 2005; 9: R591-595.

16. Durward A, Tibby SM, Skellett $S$ et al.: The strong ion gap predicts mortality in children following cardiopulmonary bypass surgery. Pediatr Crit Care Med 2005; 6: 281-285.

17. Antonini B, Piva $S$, Paltenghi $M$ et al.: The early phase of critical illness is a progressive acidic state due to unmeasured anions. Eur J Anaesthesiol 2008; 25: 566-571. doi: 10.1017/ S0265021508003669. doi: 10.1017/S0265021508003669.

18. Rocktaeschel J, Morimatsu H, Uchino S, Bellomo R: Unmeasured anions in critically ill patients: can they predict mortality? Crit Care Med 2003; 31: 2131-2136.

19. Gunnerson KJ, Srisawat N, Kellum JA: Is there a difference between strong ion gap in healthy volunteers and intensive care unit patients? J Crit Care 2010; 25: 520-524. doi: 10.1016/j. jcrc.2009.11.001.

20. Tuhay G, Pein MC, Masevicius FD et al.: Severe hyperlactatemia with normal base excess: a quantitative analysis using conventional and Stewart approaches. Crit Care 2008;12: R66. doi: $10.1186 /$ cc6896.

\section{Corresponding author:}

Jakub Szrama: MD, PhD

Department of Anesthesiology, Intensive Care and Pain

Management, Medical University Hospital

Przybyszewskiego 49, 60-355 Poznań, Poland

e-mail:jakub.szrama@gmail.com

Received: 28.07.2015

Accepted: 6.01.2016 